\title{
OVARIAN ULTRASTRUCTURE AND DEVELOPMENT OF THE BLOW FLY, Chrysomya megacephala (DIPTERA: CALLIPHORIDAE)
}

\section{TARINEE CHAIWONG 1 , KOM SUKONTASON², URAI CHAISRI ${ }^{3}$, BUDSABONG KUNTALUE4, ROY C. VOGTSBERGER ${ }^{5}$ AND KABKAEW L. SUKONTASON ${ }^{*}$}

\author{
${ }^{1}$ College of Medicine and Public Health, Ubon Ratchathani University, Ubon Ratchathani 34190, Thailand. \\ 2Department of Parasitology, Faculty of Medicine, Chiang Mai University, Chiang Mai 50200, Thailand. \\ 3Department of Tropical Pathology, Faculty of Tropical Medicine, Mahidol University, Bangkok 10400, Thailand. \\ 4Electron Microscopy Research and Service Center (EMRSC), Faculty of Science, Chiang Mai University, Chiang Mai 50200, Thailand. \\ 5Department of Biology, Midwestern State University, Wichita Falls, TX 76308, USA. \\ *Corresponding Author: Email- klikitvo@med.cmu.ac.th
}

Received: March 23, 2012; Accepted: May 10, 2012

\begin{abstract}
Chrysomya megacephala (F.) (Diptera: Calliphoridae) is a medically important blow fly species in many parts of the world. In this study, we examined the ovary of C. megacephala at the ultrastructural level using light microscopy (LM), scanning electron microscopy (SEM) and transmission electron microscopy (TEM). Dissection of the ovaries revealed eight stages of ovarian development, thus providing a means of estimation of the age of females based on this organ. In the initial stage I (day 0-2), freshly-emerged flies up to three days old each display piriform germaria while the follicles are not yet well differentiated. In stage II (day 3), each follicle is nearly spherical and separating from the germarium. During stage III (day 4), each follicle is now easily distinguished from the germarium and is only connected by a thin interfollicular stalk. The nurse cells are completely surrounded by the cuboidal epithelial follicular cells. In stage IV (day 5-6), each follicle is spherical and considerably enlarged; whereas, the nurse cells within are more differentiated into individual round inclusions and grouped in the follicle chamber. Stage V (day 7) marks appearance of the visible oocyte at the posterior pole of the follicle. During stage $\mathrm{VI}$ (day 8), each follicle displays oocyte expansion anteriorly to occupyfrom one-third to one-half of the total length. In stage VII (day 9) the 00cyte characteristically fills the posterior two-thirds of the total length of the follicle and in the final stage VIII (day 10), each follicle is completely filled by an oocyte and nurse cells have disappeared. The micropyle and narrow, elongate median area are clearly seen in this final stage. SEM images reveal that the ovary is covered by an ovarian envelope, which is tough and thickened in 3-day-old adult ovarioles; whereas, it becomes thin and fragile in 9-day-old adult ovarioles. TEM analysis of ovarioles of 3-day-old adult flies shows that cuboidal follicular cells containing large nuclei with visible fibrils of muscle simply encircle the large compartments of nurse cells; whereas, ovarioles of 7day-old adult flies displayed a more completely developed enclosure for the developing oocyte. This was observed by the presence of the outermost follicular cell layer with underlying eggshell, vitelline envelope, trabecular layer, and layer of granular material that surrounded the innermost oocyte.
\end{abstract}

Key words- Chrysomya megacephala, ovarian development, ultrastructure, electron microscopy

Citation: Tarinee Chaiwong, et al. (2012) Ovarian Ultrastructure and Development of The Blow Fly, Chrysomya megacephala (Diptera: Calliphoridae). International Journal of Parasitology Research, ISSN: 0975-3702 \& E-ISSN: 0975-9182, Volume 4, Issue 1, pp.-65-70.

Copyright: Copyright@2012 Tarinee Chaiwong, et al. This is an open-access article distributed under the terms of the Creative Commons Attribution License, which permits unrestricted use, distribution, and reproduction in any medium, provided the original author and source are credited.

\section{Introduction}

The Oriental latrine fly, Chrysomya megacephala (Fabricius), is a blow fly species of medical importance worldwide, whose wide distribution ranges from the Oriental, Australasian, and Oceania regions through Africa, America, Europe, and the Mediterranean [1-3]. In Thailand, C. megacephala was the most common species collected from several land use types, from the lowland of human habitations (cities, villages, paddy fields, disturbed mixed decidu- ous forests, and mixed orchards) to the mixed deciduous forested areas, which implies that it also has a broad distribution concerning ecological localities [4]. Medically, this fly species is one of public health concern based on the adults' potential as a mechanical carrier of various pathogens (bacteria, viruses, protozoa and helminth eggs) involved in human diseases [5]; while larvae are known myiasis-producing agents [6]. Moreover, C. megacephala is one of the most common species found in human cadavers. Its 
life stages (egg, larva, puparium, and adult) are often collected as entomological evidence in many forensic investigations involving human death; thereby, why this is a fly species of forensic importance $[7 ; 8]$. In view of agronomic importance, this fly species has been reported as a pollinator of mango in Australia and Taiwan $[9 ; 10]$.

Because of the medical and agronomical involvements of $C$. megacephala, this fly has been the subject of many studies, but data relevant to morphology of its reproductive system is limited $[11 ; 12]$. Investigation of the female reproductive system of flies is imperative based on the fact that such organs as the ovary aim to specifically produce numerous offspring in each generation within the relatively short life span of adults. Prior research has been conducted to investigate the ultrastructure of ovaries in many insects. Species investigated include the blow flies (Diptera: Calliphoridae), Chrysomya bezziana [13], C. megacephala [11], Cochliomyia hominivorax [14], and Calliphora erythrocephala [15]; the decapitating fly Pseudacteon wasmanni (Diptera: Phoridae) [16]; the snipe fly Rhagio lineola (Diptera: Rhagionidae) [17]; the moth midge Tinearia alternata (Diptera: Psychodidae) [18]; the dragonfly Libellula depressa [19]; the honey bee Apis mellifera [20], and the pig louse Haematopinus suis [21]. As for C. megacephala, only photomicrographs of its ovary have already been produced from light microscopy (LM) [11]. In order to fill the gap of information regarding ultrastructure and/or development of this organ in this species, the aim of this study was therefore to investigate the ovary of this fly species using LM, scanning electron microscopy (SEM) and transmission electron microscopy (TEM). This should give insight into ovarian morphology at the ultrastructural level and also into chronological ovarian development. Availability of such data should be useful as baseline biological information on C. megacephala which may be used toward fly control efforts and/or forensic entomology applications.

\section{Materials and Methods \\ Flies}

Samples of C. megacephala were derived from a natural population collected at local market places in Chiang Mai, northern Thailand, and subsequently reared. This fly colony was then maintained at ambient temperature $\left(18-27^{\circ} \mathrm{C}\right)$ under a natural light/dark photoperiod within a cabinet in the rearing room of the Department of Parasitology, Faculty of Medicine, Chiang Mai University. Flies were reared based on a previously described protocol [22]. Adults were reared on two kinds of food: (i) a mixture of $10 \%$ (w/v) multivitamin syrup solution and (ii) fresh pork liver (used as both a food source and oviposition site).

\section{Dissection of ovary and use of light microscopy (LM)}

To assess the changes in development of the ovary under light microscopy, females reared from the same batch of eggs were first sacrificed by transferring them from the rearing cage via a transparent tube into a freezer set at $4^{\circ} \mathrm{C}$ and left for a period of 15 min. This procedure was repeated daily beginning with newly emerged female flies (0-day-old) up until ones that were 9-daysold were being sacrificed. Ovaries were obtained by dissection in phosphate buffer saline ( $\mathrm{pH}$ 7.4) on a glass slide under a dissecting microscope (Olympus, Japan) at $x 3$ magnification. The glass slide containing the ovary was transferred for examination under a compound microscope (Olympus, Japan) and photographed using a mounted digital camera (Nikon ${ }^{\circledR}$, Tokyo, Japan).

\section{Scanning electron microscopy (SEM)}

The dissection method in this SEM investigation was the same as that used for examination with LM. Although for this study, whole ovaries were dissected from 3-day-old and 7 or 9-day-old females and fixed in $2.5 \%$ glutaraldehyde in phosphate buffer (PB) at a pH of 7.4 at $4^{\circ} \mathrm{C}$ for $24 \mathrm{~h}$. After primary fixation, the samples were rinsed with PB twice at 15-min intervals. The rinsed samples were then placed in $1 \%$ osmium tetroxide as a post-fixative at room temperature for 2-3 h. Subsequently, they were rinsed twice with PB and dehydrated gradually at 30-min intervals through a series of increasing alcohol concentrations $(10 \%, 30 \%, 50 \%, 70 \%, 80 \%$, $90 \%, 95 \%$ ) followed by two soakings in $100 \%$ alcohol. Acetone was then applied twice for $30 \mathrm{~min}$. Following dehydration, the specimens were critical point dried (CPD), then attached gently to aluminum stubs using double-stick tape and coated with gold (Au) in a sputter-coating apparatus before being viewed with a JEOL JSM-5910LV scanning electron microscope (JEOL, Japan).

\section{Transmission electron microscopy (TEM)}

In TEM investigation, the ovaries were dissected from 3 and 7-day -old females. The dissection procedure was the same as that in the LM study and the fixation procedures for the TEM study were the same as those described for the SEM study. After postfixation, whole ovaries were dehydrated as previously described and placed in acetone for $2 \mathrm{~h}$ before transferring to a resin and an acetone mixture at a ratio of $1: 3$ for $24 \mathrm{~h}, 1: 1$ for $24 \mathrm{~h}$ and $3: 1$ for $24 \mathrm{~h}$, in order to replace the acetone in the specimens with resin and ensure complete embedding. This process was repeated twice for each specimen in 100\% resin for $3 \mathrm{~h}$. Specimens were embedded in Spurr's resin by placing them into a plastic block template, and incubating at $70^{\circ} \mathrm{C}$ for $24 \mathrm{~h}$. Semi-thin sections $(0.5$ $\mu \mathrm{m}$ thick) for LM study were cut with an Ultramicrotome (Becthai, USA) from the block of 3-day-old female specimens only and then stained with $1 \%$ methylene blue and $1 \%$ azure II (1:1). These sections were then examined using a light microscope (Olympus ${ }^{\circledR}$, Tokyo, Japan). The ultrathin sections $(90 \mathrm{~nm})$ were cut and stained with uranyl acetate and lead citrate before being observed in a Hitachi $\mathrm{H} 700$ transmission electron microscope (Japan) operated at $100 \mathrm{kV}$. Terminology used in describing the eggshell follows that of Margaritis and Mazzini [23].

\section{Results}

The female internal reproductive organs of $C$. megacephala consist of a pair of ovaries, a pair of lateral oviducts, a common oviduct, three spermathecae, a pair accessory glands, and the genital chamber (Fig. 1a, b). The two ovaries of 3-day-old C. megacephala are small round bodies that are white in color and the ovarioles can be observed within each ovary during egg development (Fig. 1a). SEM observation revealed an outer ovarian envelope surrounding the entire ovary over both dorsal and ventral surfaces (Fig. 2a). This envelope was tough and thickened in 3day-old adult flies (Fig. 2b). A heavy penetration of oxygensupplying tracheae was specifically found on the dorsal surface of each ovary. The ovaries and ovarioles of 9-day-old females (Fig. $1 \mathrm{~b})$ were larger and more developed than those of 3-day-old females. They reached a maximum observed size of nearly $4 \mathrm{~mm}$ in diameter by nine days of age and developed eggs fully filled each 
ovary (Fig. 1b). SEM imaging revealed that the ovarian envelope transforms to being very thin and fragile in 9-day-old adult flies and the tracheae appear to be greatly reduced (Fig. 2c).
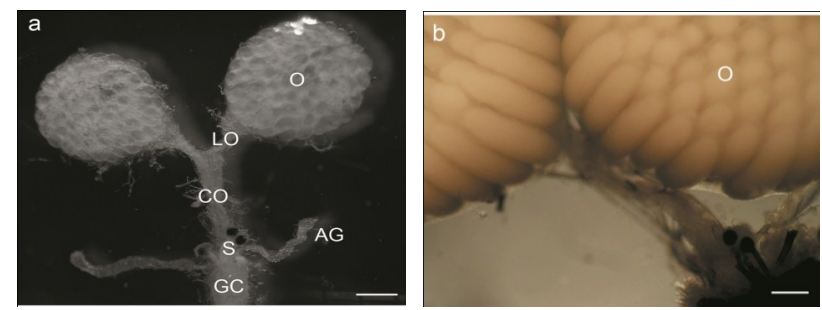

Fig. 1- Light micrographs of female reproductive organs of Chrysomya megacephala. (a) Reproductive organ system of 3day-old female consisting of a pair of ovaries (0), pair of lateral oviducts (LO), common oviduct (CO), pair of accessory glands $(A G)$, three spermathecae $(S)$ and the genital chamber. Bar $=50$ $\mu \mathrm{m}$. (b) 10-day-old ovaries (0) containing mature oocytes. Bar = $200 \mu \mathrm{m}$
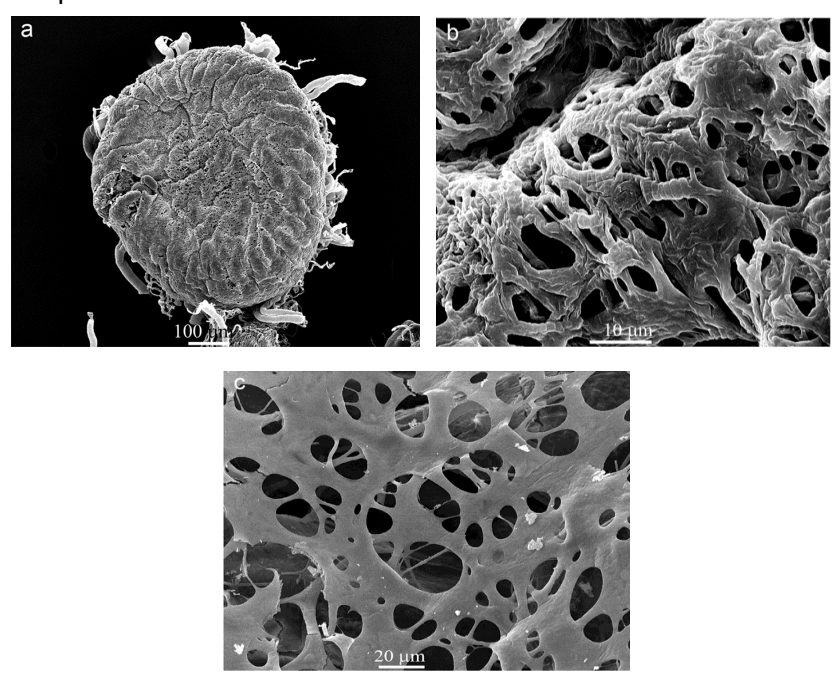

Fig. 2- Scanning electron micrographs of an ovary of Chrysomya megacephala. (a) Ventral surface of ovary of 3-day-old fly. Note the heavy penetration of tracheae specifically into the dorsal surface. (b) Detail of 3-day-old ovary highlighting tough, thickened ovarian envelope. (c) Detail of 9-day-old ovary highlighting thin, fragile ovarian envelope. Note the tears in envelope.

\section{Stages of ovarian development}

In the present study, the ovarioles of $C$. megacephala were observed for changes from day 0 (just after emergence) until 10-dayold under ambient temperature conditions of $18-27^{\circ} \mathrm{C}$ during the study period. The observations of the ovarian stages were conducted using fresh preparations in which the ovarioles were placed on a slide and covered with a cover slip. They were then examined and measured under an ordinary light microscope. The ovarioles of $C$. megacephala are of the polytrophic ovariole type [24]. The characterization of each stage of ovariole maturation was conducted in a similar manner to the way in which these stages have been outlined in other blow fly species, such as Lucilia cuprina [25, 26], C. bezziana [13], C. hominivorax [14], Chrysomya putoria [27] and Chrysomya albiceps [28]. The correspondence between the classifications used to describe the stages of ovarian development of $C$. megacephala (Fig. 3) is provided and described as follows:

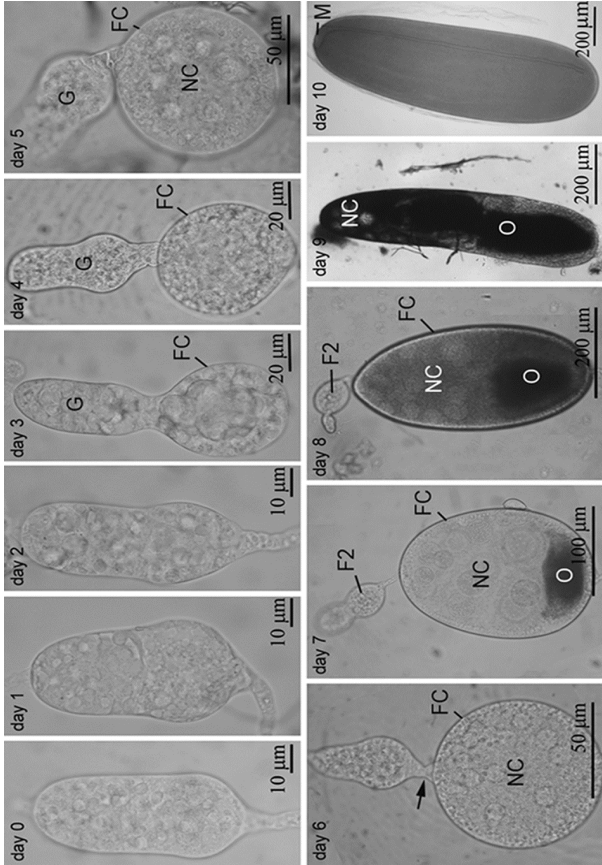

Fig. 3- Light micrographs showing stages of ovarian development of $C$. megacephala. Stage I (day 0-2) displays undifferentiated ovarioles. Stage II (day 3) shows nearly spherical follicle separating from germarium. Stage III (day 4) shows complete separation of follicle from germarium. Stage IV (day 5-6) displays enlarged spherical follicle with distinctive nurse cells within. Arrow in day 6 indicates interfollicular stalk. Stage $V$ (day 7 ) is characterized by presence of developing oocyte at posterior pole of follicle. Stage $\mathrm{VI}$ (day 8) shows developing oocyte expanded to occupy posterior one-third to one-half of elongating follicle. Stage VII (day 9) denotes oocyte filling posterior two-thirds of greatly elongated follicle. Stage VIII (day 10) demonstrates the oocyte fully occupying follicle as mature egg. Micropyle and median area are visible. $(F C=$ follicle cells; $F 2$ = secondary follicle; $G=$ germarium; $N C=$ nurse cells; $\mathrm{M}=$ micropyle; $\mathrm{O}=$ oocyte)

Stage I (Day 0-2)- In the initial stage of development, young flies that have just emerged up to those that are two days old display visibly undifferentiated ovarioles in which each ovariole has a translucent piriform germarium. The follicles are not yet well differentiated from the germarium in this stage.

Stage II (Day 3)- Stage II clearly shows the nearly spherical follicle in the process of distinctly separating from the apical germarium by the presence of the constriction between germarium and follicle. The nurse cells are present as a group clustered in the central region of the follicle and are surrounded by the thick layer of follicular cells.

Stage III (Day 4)- The more nearly spherical follicle is now completely separated from the germarium with its only connection being that of an interfollicular stalk. The nurse cells are completely surrounded by the cuboidal epithelial follicular cells and an even more distinct separation has appeared between the germarium and the follicle in the formation of the first egg chamber.

Stage IV (day 5-6)- The follicle is completely spherical and enlarged considerably and contains the nurse cells which are now more differentiated into individual round units that are scattered within the follicle chamber. 
Stage V (Day 7)- This stage is characterized by the first indication of the visibly developing oocyte at the posterior pole of the follicle; whereas, the rest of the follicle is filled with the aggregation of engorged nurse cells. The follicle epithelium encapsulating the follicle is clearly visible and a second follicle can be seen forming in the posterior end of the germarium in this stage.

Stage VI (Day 8)- As a result of differentiation, this stage shows the follicles elongating into an oval shape as the oocyte expands anteriorly to fill one-third to one-half of the total follicle length.

Stage VII (Day 9)- This stage is characterized by great elongation and slight narrowing of the follicle as the oocyte continues to grow and expand anteriorly to fill the posterior two-thirds of the total follicle length. In the process, the nurse cells are reduced to occupy only the anterior cone of the follicle. The encapsulating follicular cells are still present, but due to the growth of the oocyte within they have been transformed to a squamous shape.

Stage VIII (Day 10)- Due to advanced differentiation in this final stage, the developed oocyte now fills the entire follicle; whereas, the nurse cells have been depleted and disappear. The mature oocytes or eggs of C. megacephala are elongate, averaging 1.40 $\mathrm{mm}$ in length and $0.40 \mathrm{~mm}$ in width. In the mature egg, the micropyle is visible and a narrow, elongate median area is also clearly seen.

\section{Development of the ovarioles}

This portion of the study is based on the TEM images of the development of the ovarioles in 3- and 7-day-old adults of $C$. megacephala. The cellular changes in ovarioles during development of 3-day-old and 7-day-old adult flies are described.

Morphology of the ovariole of 3-day-old adult flies: In 3-day-old adult flies, sections of the anterior terminal cells revealed a follicular cell layer and germarium (Fig. 4a-c). The follicular cells contain large nuclei and are infiltrated with numerous oxygen-supplying tracheoles (Fig. 4a). Fibrils of muscle were also detected within this layer (Fig. 4a,b). Within the germarium, the cytoplasm revealed variable sizes of mitochondria and rough endoplasmic reticulum (Fig. 4c). Based on the sections taken at the posterior region, semi-thin sectioning revealed the large cuboidal epithelial follicular cells (Fig. 4d) encircling the large compartment of nurse cells containing large nuclei with aggregations of chromatin.

Morphology of the ovariole of 7-day-old adult flies: In a 7-day-old adult fly ovariole, the formation of the chorion appears more complete as evidenced by the presence of the outermost follicular cell layer, the eggshell, the vitelline envelope, the trabecular layer (Fig. 5a), the layer of granular material and the innermost oocyte. The follicular cells contain large nuclei with condensed chromatin, while their cytoplasm is filled with scattered and variable sized vesicles of likely secretory materials (Fig. 5b). Close-up investigation by TEM highlighted the outermost follicular layer and eggshell overlying the thick vitelline envelope and trabecular layer (Fig. 5c). At this stage of almost complete development, the eggshell is intimately structured with several layers, beginning with the outermost exochorion and moving inward through the outer endochorion, pillar, inner endochorion, innermost chorionic layer, and finally the wax layer (Fig. 5d). Focusing beneath the vitelline envelope, a continuity of minute microvilli lines the interface with the closely underlying trabecular layer (Fig. 5e). Moreover, TEM investigation of the 7-day-old adult fly ovariole revealed a thick layer of fine granular material adjacent to the central oocyte (Fig. 5f, oocyte marked by asterisk).

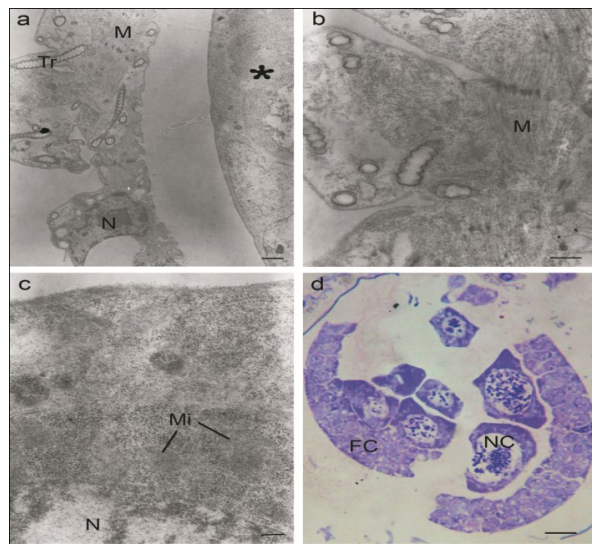

Fig. 4- Micrographs of ovarioles of 3-day-old adult C. megacephala. (a) Transmission electron micrograph of anterior terminal cells reveal follicular cell containing large nucleus $(\mathrm{N})$. Infiltration of numerous tracheoles $(\mathrm{Tr})$ were observed and fibrils of muscle $(\mathrm{M})$ were present. Asterisk marks germarium. Bar $=1 \mu \mathrm{m}$. (b) Transmission electron micrograph of follicular cell layer focusing on fibrils of muscle (M). Bar $=0.5 \mu \mathrm{m}$. (c) Transmission electron micrograph of cytoplasm of germarium reveals large nucleus $(\mathrm{N})$ and mitochondria (Mi). Rough endoplasmic reticulum was also seen. Bar $=0.2 \mu \mathrm{m}$. (d) Light micrograph of semi-thin section from posterior region revealed large cuboidal epithelial follicular cells (FC) encircling the large compartment of nurse cells (NC). Bar $=5 \mu \mathrm{m}$

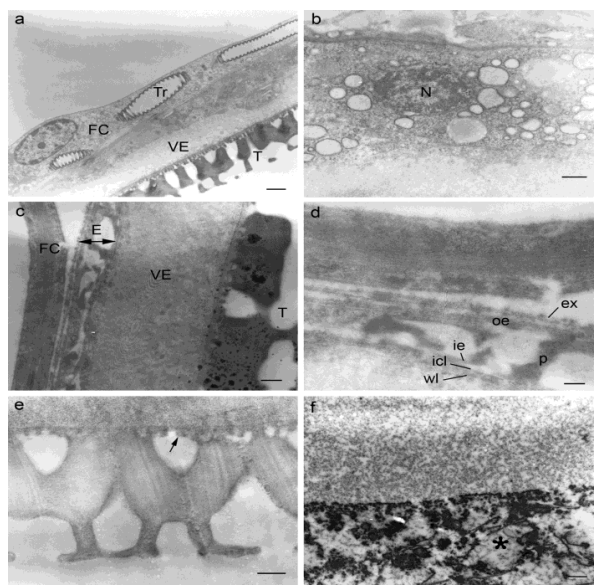

Fig. 5- Transmission electron micrographs of ovarioles of 7-dayold adult C. megacephala. (a) Formation of chorion showing outermost follicular cell layer (FC), eggshell, vitelline envelope $(V E)$, and inner trabecular layer $(T)$. Penetration of numerous tracheoles $(\mathrm{Tr})$ were observed. Bar $=1 \mu \mathrm{m}$. (b) Follicular cell containing large nucleus $(\mathrm{N})$ and cytoplasm filled with scattered and variable sized vesicles of likley secretory materials. Bar $=0.5 \mu \mathrm{m}$. (c) Close-up of chorion revealing structure of follicular layer (FC), eggshell (E), vitelline envelope (VE) and trabecular layer (T). Bar $=0.5 \mu \mathrm{m}$. (d) Detail of eggshell identifying outermost exochorion (ex), outer endochorion (oe), pillar (p), inner endochorion (ie), innermost chorionic layer (icl), and the wax layer (wl). Bar $=0.2$ um. (e) Continuity of minute microvilli (arrow) lined beneath vitelline envelope. Bar $=0.5 \mu \mathrm{m}$. (f) Thick layer of fine granular material adjacent to central oocyte (asterisk). Bar $=1 \mu \mathrm{m}$ 


\section{Discussion}

Research focused on the reproductive biology of insects concerning sexual maturation is of utmost significance if fly species are ever going to be controlled. This is especially true for those species capable of producing large numbers of offspring by each female. In this regard, the current research was directed toward studying the ultrastructural morphology and development of the ovary organ of the female reproductive system in $C$. megacephala using LM, SEM and TEM. Similar to other flies, C. megacephala has polytrophic ovarioles in which the ovary houses many ovarioles which differentiate synchronously to form numerous mature oocytes ready for fertilization to produce offspring.

It was discovered in this study through SEM imaging that in young 3-day-old female C. megacephala with immature ovarian development that they possess a very tough, thickened ovarian envelope that encapsulates the ovary. As the oocytes expand and mature during development in the ovarioles of each ovary, correspondingly the ovarian envelope becomes quite stretched resulting in a very thin and fragile encapsulating membrane in older age flies. Nonetheless, the membrane seems to suffice in preventing dislodgement of the ovarioles in the hemocoelom. More precise for use in age determination of $C$. megacephala was our information concerning chronological differentiation in stage of ovarian development based on LM study. Yet, this method for estimating age of females is similar to many already published for other fly species, such as the blow fly, C. hominivorax [14], the tsetse flies, Glossina pallidipes, G. palpalis fuscipes and G. brevipalpis (Diptera: Glossinidae) [29], and the Caribbean fruit fly, Anastrepha suspensa (Diptera: Tephritidae) [30].

In determining the stages of ovarian development in flies, slight differences occur between the various studies upon comparison of the number of ovarian stages and variable descriptions that have been reported. Results of the current study indicate that female $C$. megacephala complete egg development in eight stages under fluctuating ambient temperature $\left(18-27^{\circ} \mathrm{C}\right)$. By comparison, the other blow fly species that have been studied [31] exhibit ten overall stages of ovarian development instead of only eight as was reported for C. megacephala in this study [14]. In C. megacephala, stage I represents adult life from day 0 (just after emergence) to day 2; whereas, stage I was assigned to mature pupae before emergence in C. bezziana, suggesting a longer period of development in the former species during this designated stage. Stage $\mathrm{VI}$ in C. megacephala demonstrated that the developing oocyte fills one-third to one-half of the total follicle length; whereas, this condition is related with stages VI and VII in C. bezziana [13] or stage $\checkmark$ in $C$. hominivorax [14]. On the other hand, the mature egg with presence of the micropyle is associated with stage VIII in C. megacephala but is correlated with stage $X$ in $C$. hominivorax [14]. Likewise, stage VIII observed in C. megacephala, which again is characterized by the mature oocytes, was correlated with stage $\mathrm{VI}$ in 7-9 day-old adult $A$. suspensa reared at $23-27^{\circ} \mathrm{C}$ [30].

The development of the follicular epithelium of 3- and 7-day-old adults of $C$. megacephala undergoes differentiation during oogenesis. TEM micrographs presented herein provide distinction in development of the ovariole in younger and older females. Micrograph sections of a 3-day-old adult ovariole revealed a thick cuboidal epithelial follicular cell layer (Fig. 4d) without any indication of organized laminated structure of the eggshell. In contrast, micrographs of a 7-day-old adult ovariole displayed a flattened follic- ular cell layer overlying the eggshell, vitelline envelope, and trabecular layer. A thick vitelline envelope was observed beneath the eggshell of $C$. megacephala in the 7-day-old adult ovariole (Fig. 5c), which is similar to what has been seen in another blow fly species, Phormia regina [23]. As for the eggshell itself, the fine detailed structure observed in C. megacephala is comprised of several layers similar to that in Drosophila melanogaster [32]. The characteristic changes in the development of the follicular epithelium (i.e., chorionogenesis) in this blow fly species are even quite similar to those described in the stoneflies Perla marginata and $P$. pallida (Plecoptera: Perlidae) [33].

The reproductive status of flies may be used to imply approximate generation times or time between egg batches within a population. Information pertaining to ascertaining whether adults are young, recently emerged versus elderly flies would be helpful in clarifying estimations of population size, as has been recorded in C. megacephala and C. putoria [34]; the bush fly Musca vetustissima (Diptera: Muscidae) [35], or even in disease surveillance studies of vector mosquitoes [36]. Hence the stages of ovarian development in C. megacephala can be a useful tool for age determination relating to population potential of this species in the field. Increased temperature governs faster development of the ovariole. Egg maturation research conducted at $24^{\circ} \mathrm{C}$ showed that $\mathrm{C}$. hominivorax eggs took $152 \mathrm{~h}$ to reach maturity, while at $30^{\circ} \mathrm{C}$ maturation time was reduced to $80 \mathrm{~h}$ [14]. Ovarian development of C. megacephala under an ambient temperature range of $18-27^{\circ} \mathrm{C}$ in this study took $\sim 10$ days to reach development of a mature oocyte. This is similar to the 10-13 days required for complete maturation in the same species reared at $25 \pm 2^{\circ} \mathrm{C}$ [37]. Thus, the information from the current study not only supports previous findings of the fast ovarian development of this species, but also the capacity to produce numerous offspring or eggs in each generation. Our data obtained from laboratory observations reveal that a single dissected female can contain from 262-329 mature ovarioles $(n=40)$, indicating the remarkably large reproductive potential of each female. In addition, the average longevity of female $C$. megacephala reared in the laboratory, using $10 \%$ sugar solution as their food source, was 29 days (range: 5-47 d). This suggests a relatively long life span for the species if appropriate environmental conditions are present. Information from the current study pertaining to the capability of fast ovarian development, large production of eggs, and relatively long life span of this fly species are of special concern if fly control strategies are being contemplated. This is especially important in areas with tropical ambient temperatures and/or areas in which $C$. megacephala may be implicated in mechanical transfer of disease-causing agents.

\section{Acknowledgments}

We appreciate the support from the Thailand Research Fund (RMU4980007 to KLS) and the Royal Golden Jubilee Ph.D. Program (PHD/0113/2547 to TC). We also thank the Faculty of Medicine and Chiang Mai University for subsidizing publication costs. This work was presented as a poster presentation at the Microscopy Conference held in Kiel, Germany from August 28- September 2, 2011.

\section{References}

[1] Kurahashi H. and Magpayo F.R. (2000) Raffles Bull Zool. Suppl. 9, 1-78. 
[2] Martinez-Sanchez A., Marcos-Garcia M.A. and Rojo S. (2001) Pan-Pacific Entomol., 77, 240-243.

[3] Ebejer M.J. (2007) Entomologist's Monthly Magazine, 143, 165-170.

[4] Ngoen-klan R., Moophayak K., Klong-klaew T., Irvine K.N., Sukontason K.L., Prangkio C., Somboon P. and Sukontason K. (2011) Parasitol. Res., 109, 1279-1292.

[5] Greenberg B. (1973) Princeton University Press, New Jersey, USA.

[6] Zumpt F. (1965) Butterworths, London.

[7] Early M. and Goff M.L. (1986) J. Med. Entomol., 23, 520-531.

[8] Sukontason K., Narongchai P., Kanchai C., Vichairat K., Sribanditmongkol P., Bhoopat T., et al. (2007) Parasitol. Res., 101, 1417-1423.

[9] Anderson D.L., Sedgley M., Short J.R.T. and Allwood A.J. (1982) Aust. J. Agr. Res., 33, 541-548.

[10]Hu T., Len C.H. and Lee B.S. (1995) Chin. J. Entomol., 15, 103-111.

[11]Bansal A. and Murad H. (1987) Jpn. J. Sanit. Zool., 38, 233238.

[12]Sukontason K.L., Chaiwong T., Chaisri U., Kurahashi H., Sanford M. and Sukontason K. (2011) J. Parasitol. Res, doi:10.1155/2011/690863.

[13]Spradbery J.P. and Sands P.A. (1976) Int. J. Insect Morphol. Embryol., 5, 409-421.

[14]Adams T.S. and Reinecke J.P. (1979) J. Med. Entomol., 15, 472-483.

[15]Anan'ina T.V., Vedernikov A.E., Khodzhanov A.E. and Stegnii V.N. (2010) Cell Tissue Biol., 4, 192-198.

[16]Zacaro A.A. and Porter S.D. (2003) Arthropod. Struct. Dev., 31, 329-337.

[17]Kubrakiewicz J., Jablonska A., Mazurkiewicz M. and Bilinski S.M. (2003) Genesis, 36: 214-224.

[18]Mazurkiewicz M. and Kubrakiewicz J. (2008) Int. J. Dev. Biol., 52, 267-278.

[19]Gaino E., Piersanti S. and Rebora M. (2008) Tissue \& Cell, 40, 317-324.

[20]Neves C.A., Gitirana L.B. and Serrao J.E. (2003) Braz. J. Biol., 63, 683-690.

[21]Zelazowska M. (2005) Folia Biol. (Krakow), 53, 51-60.

[22]Bunchu N., Sukontason K.L., Olson J.K., Kurahashi H. and Sukontason K. (2008) Parasitol. Res., 102, 419-429.

[23]Margaritis L.H. and Mazzini M. (1998) In Harrison FW, Locke $M$ (eds.), Wiley-Liss, Inc., New York, 995-1037.

[24]Buning J. (1998) In Harrison FW, Locke M (eds.), Wiley-Liss, Inc., New York, 897-932.

[25]Vogt W.G., Woodburn T.L. and Tyndale-Biscoe M. (1974) Bull Entomol. Res., 64, 365-370.

[26]Beattie G.A.C. and Cheney J. (1979) Aust. J. Zool., 27, 331347.

[27]Avancini R.M.P. and Prado A.P. (1986) Int. J. Insect Morphol. Embryol., 15, 375-384.

[28]Mustafa M. (1990) J. Egypt Vet. Mes. Ass., 50, 117-132.

[29]Saunders D.S. (1962) Bull Entomol. Res., 53, 579-595.

[30]Kendra P.E., Montgomery W.S., Epsky N.D. and Heath R.R. (2006) Florida Entomol., 89, 144-151.

[31]Bedo D.G. (1992) Genome, 35, 294-303.

[32]Margaritis L.H., Kafatos F. and Petri W. (1980) J. Cell Sci., 43,
1-35.

[33]Rosciszewska E. (1995) Int. J. Insect. Morphol. Embryol., 24, 253-271.

[34]Avancini R.M. and Silveira G.A. (2000) Mem. Inst. Oswaldo Cruz., 95, 259-264.

[35]Matthiessen J.N., Hall G.P. and Chewings V.H. (1986) J. Aust. Entomol. Soc., 25, 141-147.

[36]Woodbridge F.A. and Walker E.D. (2002) Academic Press, New York, 203-262.

[37]Linhares A.X. and Avancini R.M.P. (1989) Med. Vet. Entomol, 3, 293-295. 